\title{
Erratum
}

\section{Pre-transplant positron emission tomography (PET) using fluorine-18- fluoro-deoxyglucose (FDG) predicts outcome in patients treated with high-dose chemotherapy and autologous stem cell transplantation for non-Hodgkin's lymphoma}

Cremerius et al

Correction to: Bone Marrow Transplantation (2002) 30, 103-111. doi:10.1038/sj.bmt.1703607

Bone Marrow Transplantation (2002) 30, 707. doi:10.1038/sj.bmt.1703726

In the abstract of the above paper it was incorrectly stated that 'Partial metabolic response (PMR) was defined as a $<25 \%$ decrease of SUV between successive PET scans.' The correct version appears below:

Partial metabolic response (PMR) was defined as a $>25 \%$ decrease of SUV between successive PET scan. 